\title{
Effects of Heavy-Ions on Soft-Magnetic Metallic Glasses Studied by Diffraction of Synchrotron Radiation
}

\author{
S. Michalik ${ }^{a, *}$, M. Pavlovic ${ }^{b}$, J. Gamcova ${ }^{c}$, P. SovaK $^{c}$ And M. Miglierini ${ }^{b, d}$ \\ ${ }^{a}$ Diamond Light Source Ltd., Harwell Science and Innovation Campus, Didcot, Oxfordshire OX11 0DE, UK \\ ${ }^{b}$ Slovak University of Technology in Bratislava, Faculty of Electrical Engineering and Information Technology, \\ Ilkovicova 3, 81219 Bratislava, Slovakia \\ ${ }^{c}$ Institute of Physics, Faculty of Sciences, P.J. Safarik University, Park Angelinum 9, 04154 Košice, Slovakia \\ ${ }^{d}$ Department of Nuclear Reactors, Czech Technical University in Prague, Prague 180 00, Czech Republic \\ In this work, influence of ${ }^{238} \mathrm{U}$ swift $(5.9 \mathrm{MeV} / \mathrm{u})$ heavy ions on the as-prepared $\mathrm{Fe}-\mathrm{Cu}-\mathrm{Nb}-\mathrm{Si}-\mathrm{B}$ metallic \\ glass was investigated by in situ temperature X-ray diffraction of synchrotron radiation. It was observed that ion \\ irradiation strongly affected the temperature evolution of the parameters of the first diffuse peak. It is hypothesized \\ that ion irradiation induced structural rearrangement that increased the degree of disorder of the amorphous \\ structure. During heat treatment, structural relaxation and annealing out of this ion-induced degradation took \\ place. Consequently, the original structure was recovered as demonstrated by the behaviour of the first diffuse \\ peak broadening and devitrification process.
}

DOI: 10.12693/APhysPolA.131.657

PACS/topics: 61.05.cp, 75.50.Lk, 61.43.Dq

\section{Introduction}

Metallic glasses (MGs) represent the group of materials lacking a long-range atomic-scale structure. Fe-based MGs are additionally well recognized as excellent softmagnetic materials [1]. Due to their homogeneous disordered structure, they are expected to be more resistant to radiation damage than their crystalline counterparts. This is the reason why the Fe-based MGs are considered as appropriate materials for applications in radiation environment, such as accelerator radio-frequency cavities [2]. Therefore, studies of the ion-induced damage of the Fe-based MGs are of high importance. However, these studies showed that at some ion fluences, the macroscopic magnetic properties (e.g. magnetic susceptibility) of MGs start rapidly degrading [3-5]. Further investigations are needed to understand physical nature of the observed degradation and its correlation with microscopic structural modifications. It has been showed that ion bombardment with $\approx 100 \mathrm{keV} \mathrm{N}$ ions at fluences of $\approx 10^{16}$ to $10^{17}$ ions $/ \mathrm{cm}^{2}$ caused microstructural modifications in subsurface regions of the $\mathrm{Fe}_{81} \mathrm{Mo}_{10} \mathrm{Cu}_{1} \mathrm{~B}_{10}$ NANOPERM-type alloy [6]. Increased hardness and Young's modulus in the $\mathrm{Ti}_{45} \mathrm{Cu}_{45} \mathrm{Zr}_{5} \mathrm{Ni}_{5} \mathrm{Sn}_{5} \mathrm{MG}$ is accompanied by the shortening of atomic pairs [7]. The influence of swift (few $\mathrm{MeV}$ per nucleon) heavy-ion bombardment on the amorphous structure of binary and ternary Fe-B-based MGs and VITROPERM-type alloy has been investigated by means of small angle X-ray scattering (SAXS) and X-ray diffraction (SXD) of synchrotron radiation, respectively $[8,9]$. SAXS proved creation of

\footnotetext{
* corresponding author; e-mail: stefan.michalik@diamond.ac.uk
}

ion tracks of cylindrical shapes with radius about 5 to $10 \mathrm{~nm}$. SXD helped to describe structural relaxation processes after swift heavy-ion irradiation.

The aim of this study is to investigate the structural changes induced by swift $\mathrm{U}$ ions on the amorphous structure of $\mathrm{Fe}_{73} \mathrm{Cu}_{1} \mathrm{Nb}_{3} \mathrm{Si}_{16} \mathrm{~B}_{7} \mathrm{MG}$ and its relaxation processes.

\section{Experimental procedure}

The amorphous $\approx 23 \mu \mathrm{m}$ thin ribbons with the composition of $\mathrm{Fe}_{73} \mathrm{Cu}_{1} \mathrm{Nb}_{3} \mathrm{Si}_{16} \mathrm{~B}_{7}$ were prepared by the melt spinning technique. The as-prepared ribbon samples of $\approx 5 \times 20 \mathrm{~mm}^{2}$ were irradiated in vacuum by $5.9 \mathrm{MeV} / \mathrm{u}$ ${ }^{238} \mathrm{U}$ ions at fluences $5 \times 10^{11}, 10^{12}$ and $5 \times 10^{12} \mathrm{ions} / \mathrm{cm}^{2}$. The non-irradiated as-prepared sample served as a reference. The influence of the swift heavy-ion irradiation on the samples' structure was studied by synchrotron X-ray diffraction (SXD). The SXD experiments were carried out at the P02.1 beamline at DESY Hamburg using the photon energy of $59.923 \mathrm{keV}$ (wavelength of $0.2069 \AA$ ). The samples were heated from room temperature up to $580^{\circ} \mathrm{C}$ and cooled down to $200^{\circ} \mathrm{C}$ at the heating rate of $10^{\circ} \mathrm{C} / \mathrm{min}$. During the heat treatment, the continuous acquisition of X-ray diffraction patterns was performed in transmission mode with a two-dimensional Perkin Elmer 1621 detector. The acquisition time of one diffraction image was $20 \mathrm{~s}$. The obtained $2 \mathrm{D}$ diffraction images were integrated along the radius of the diffraction circles in $Q$ space using the Fit2D software [10].

\section{Results}

Figure 1 displays diffraction profiles of all the irradiated specimens together with the non-irradiated one. The intensity curves $I(Q)$ s consist of a broad diffraction peak at $3.08 \AA^{-1}$ followed by series of damped oscillations observable up to $12 \AA^{-1}$ reflecting the amorphous character 
of the studied samples. The absence of any sharp Bragg peaks corroborates that there is no crystalline phase after ion irradiation. Structural changes induced by the ion irradiation were evaluated from the width/broadening, $w$, position, $Q$, and amplitude/intensity, $A$, of the first diffuse peak (FDP) that was fitted by a pseudo-Voigt function in the interval from 2.3 to $3.9 \AA^{-1}$. It is seen that the peak broadening systematically increases with the irradiation fluence (see the inset in Fig. 1). It means that ion irradiation causes an increase of the disorder of the amorphous structure.

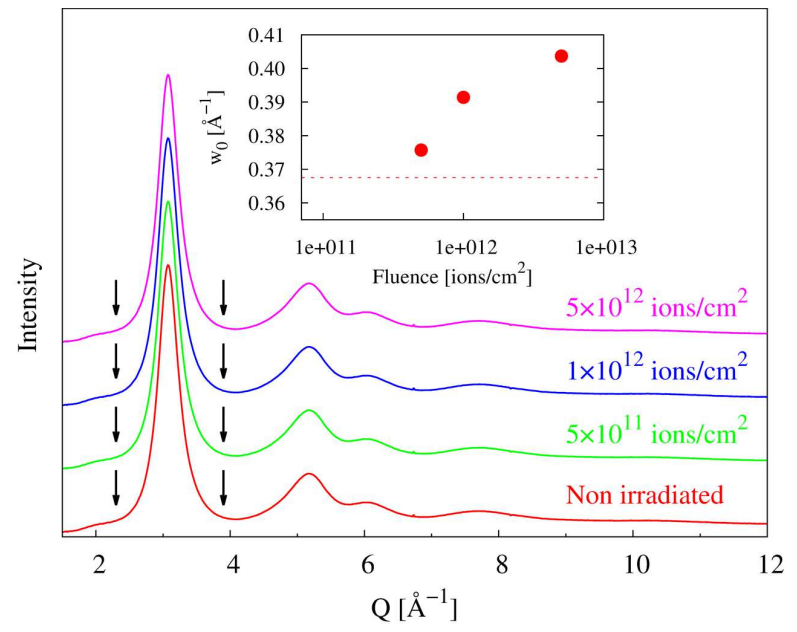

Fig. 1. Room-temperature diffraction profiles of the samples irradiated by $\mathrm{U}$ ions with the indicated fluences. The intensity curves are vertically offset for clarity. The grey arrows indicate the range of the first diffuse peak (FDP) fitted by the pseudo-Voigt function. The inset shows the width of the FDP as a function of ion fluence. The dashed line indicates the value for the nonirradiated sample.

In order to follow the influence of ion irradiation on the thermal stability of the investigated MG, the in situ SXD measurements were realized. Figure 2 shows the normalized peak position, $Q_{T} / Q_{0}$, the normalized peak broadening, $w_{T} / w_{0}$, and the normalized amplitude, $A_{T} / A_{0}$, as a function of temperature.

The $Q_{T} / Q_{0}$ behaviour is practically identical for all the specimens up to $290^{\circ} \mathrm{C}$. The $Q_{T} / Q_{0}$ curves move linearly towards lower values. Then a small "hump" representing a minimum of the curve slope is appearing at $380-400^{\circ} \mathrm{C}$. Interestingly, the significance of this hump increases with the irradiation fluence.

The peak broadening depends strongly upon the irradiation conditions as well. The $w_{T} / w_{0}$ curves firstly increase modestly with temperature following the same values for all samples. At certain temperature, they start dropping rapidly. The starting temperature of this drop is shifted considerably to lower values for higher irradiation fluences.

The temperature evolution of normalized $A_{T} / A_{0}$ amplitudes is similar for all the samples up to temperature of $290^{\circ} \mathrm{C}$ above which they start to deviate from each other. When the ion fluence increases, the difference between the irradiated and non-irradiated sample becomes more pronounced.
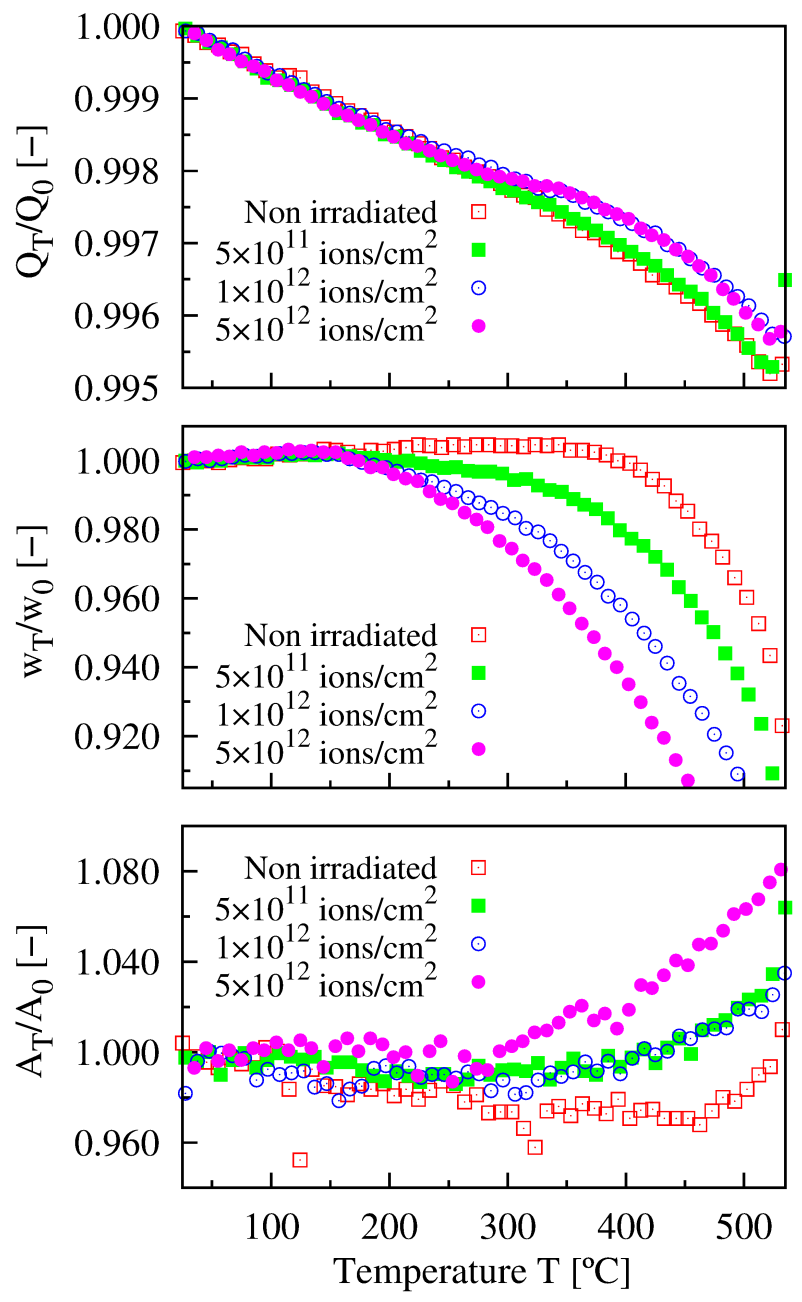

Fig. 2. The normalized (to room temperature) peak position, $Q_{T} / Q_{0}$, normalized peak broadening, $w_{T} / w_{0}$, and normalized amplitude, $A_{T} / A_{0}$, as a function of temperature.

It can be concluded that the temperature behaviour of the FDP parameters is undoubtedly influenced by the ion irradiation. Realising that the FDP reflects microstructure of the investigated alloy, the FDP modifications might be attributed to the atomic structural rearrangement induced by the ion irradiation. In contrast to the Bragg peaks of crystalline compounds, the interpretation of the FDP parameters for amorphous MGs is far away from being straightforward due to the absence of the long-range ordering. Changes in the FDP position are interpreted as free volume changes, and the increase of the FDP width is usually viewed as the increase of disorder in material.

The observed temperature behaviour of the FDP parameters (especially the width) could be explained in the 
view of structural relaxation. In general, when the temperature is increased, the recovery of the material is initialized, which is reflected by the FDP narrowing. The temperature of the material recovery could be influenced by the level of the material damage. We suppose that higher ion fluences induce more radiation damage in the MG. The different $w_{T} / w_{0}$ behaviour for investigated specimens suggests that the recovery of the specimens exposed to higher fluences starts at lower temperatures. It is worth noting that the FDP width in absolute scale (not shown here) starts to be of the same value for all the samples above $500^{\circ} \mathrm{C}$. This suggests that the amorphous structure can be recovered from radiation damage caused by swift ions using appropriate thermal annealing. This assumption is strongly supported by an additional analysis of the devitrification process of the investigated specimens. It is revealed that the crystallisation temperature is independent of applied fluence. It is the same $\left(534.7 \pm 3.3^{\circ} \mathrm{C}\right)$ for all the investigated samples within the experimental uncertainty.

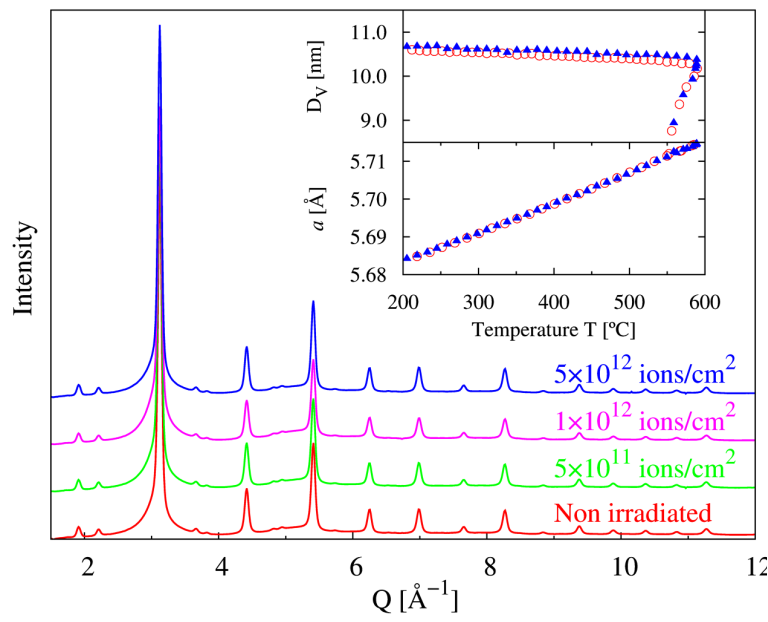

Fig. 3. Room-temperature diffraction profiles after completing the heating-treatment cycle of the samples. The insets show the temperature evolution of the lattice parameter, $a$, and grain size, $D_{V}$, of the cubic $\mathrm{Fe}_{3} \mathrm{Si}$ phase from $550{ }^{\circ} \mathrm{C}$ to $580^{\circ} \mathrm{C}$ and then during cooling down from $580^{\circ} \mathrm{C}$ to $200^{\circ} \mathrm{C}$ with the heating rate of $10^{\circ} \mathrm{C} / \mathrm{min}$. For clarity reason, only data for the nonirradiated sample (red open circles) and the sample irradiated at the fluence of $5 \times 10^{12}$ ions $/ \mathrm{cm}^{2}$ (blue solid triangles) are shown.

Figure 3 displays intensity curves collected after performing the whole heat treatment of the samples (the sample heating from room temperature up to $580^{\circ} \mathrm{C}$ and cooling back down to room temperature with the heating rate of $10^{\circ} \mathrm{C} / \mathrm{min}$ ). The formed Bragg peaks were indexed as those belonging to the cubic $\mathrm{Fe}_{3} \mathrm{Si}$ phase. No differences are observed among temperature evolutions of the lattice parameter, $a$, and crystallite size, $\mathrm{D}_{V}$, of the $\mathrm{Fe}_{3} \mathrm{Si}$ phase for particular samples, as it is demonstrated in insets of Fig. 3. The crystallite size and the lattice parameter are estimated to be about $11 \pm 1 \mathrm{~nm}$ and $5.6727 \pm 0.0004 \AA$ for all the specimens after cooling down back to room temperature.

\section{Conclusions}

In the case of swift-U-ion-bombarded amorphous $\mathrm{Fe}_{73} \mathrm{Cu}_{1} \mathrm{Nb}_{3} \mathrm{Si}_{16} \mathrm{~B}_{7}$ alloy, the in situ $\mathrm{SXD}$ was used to reveal the structural variations and relaxation processes after ion irradiation. It has been observed that temperature behaviour of the FDP parameters was apparently influenced by ion irradiation. An interpretation has been proposed that ion irradiation increased the degree of disorder of the amorphous structure. On the other hand, it has been seen that the amorphous structure can be recovered from radiation damage caused by swift ions using appropriate thermal annealing. It has been shown that the ion irradiation did not influence the devitrification process of the $\mathrm{Fe}_{73} \mathrm{Cu}_{1} \mathrm{Nb}_{3} \mathrm{Si}_{16} \mathrm{~B}_{7}$ alloy. The crystallization temperature, the lattice parameter of the $\mathrm{Fe}_{3} \mathrm{Si}$ phase, and crystallite sizes of the $\mathrm{Fe}_{3} \mathrm{Si}$ phase were identical within the experimental uncertainty for all the investigated specimens of the $\mathrm{Fe}_{73} \mathrm{Cu}_{1} \mathrm{Nb}_{3} \mathrm{Si}_{16} \mathrm{~B}_{7}$ alloy.

\section{Acknowledgments}

Parts of this research were carried out at the light source PETRA III at DESY, a member of the Helmholtz Association (HGF), using beamline P02.1. This work was supported by the grants GACR 14-12449S, VEGA 1/0182/16 and VEGA 1/0036/16.

\section{References}

[1] M.E. McHenry, M.A. Willard, D.E. Laughlin, Prog. Mater. Sci. 44, 291 (1999).

[2] A. Molvik, A. Faltens, P hys. Rev. Spec. Top. Accel. Beams 5, 080401 (2002).

[3] M. Pavlovič, M. Miglierini, E. Mustafin, T. Seidl, W. Ensinger, I. Strašík, M. Soka, Acta Phys. Pol. A 118, 754 (2010)

[4] M. Pavlovič, M. Miglierini, E. Mustafin, T. Seidl, M. Šoka, W. Ensinger, Acta Phys. Pol. A 126, 54 (2014).

[5] M. Pavlovič, M. Miglierini, E. Mustafin, W. Ensinger, A. Šagátová, M. Šoka, Radiat. Eff. Def. Solids 170, 1 (2015).

[6] M. Miglierini, M. Hasiak, Phys. Status Solidi A 213, 1138 (2016).

[7] Y. Huang, H. Fan, X. Zhou, P. Xue, Z. Ning, D. Daisenberger, J. Sun, J. Shen, Scr. Mater. 103, 41 (2015).

[8] M.D. Rodríguez, B. Afra, C. Trautmann, M. Toulemonde, T. Bierschenk, J. Leslie, R. Giulian, N. Kirby, P. Kluth, J. Non. Cryst. Solids 358, 571 (2012).

[9] S. Michalik, J. Michalikova, M. Pavlovic, P. Sovak, H.-P. Liermann, M. Miglierini, Acta Mater. 80, 309 (2014).

[10] A.P. Hammersley, S.O. Svensson, M. Hanfland, A.N. Fitch, D. Hausermann, High Press. Res. 14, 235 (1996). 